\title{
The 2010 Outbreak of Cholera among Workers of a Jute Mill in Kolkata, West Bengal, India
}

\author{
Prakash Mridha', Asit K. Biswas², R. Ramakrishnan', and Manoj V. Murhekar' \\ 'Field Epidemiology Training Programme, National Institute of Epidemiology, R-127, Tamil Nadu Housing Board, Ayapakkam, \\ Ambattur, Chennai 600 070, India and ${ }^{2}$ Strategic Planning and Sector Reform Cell, Department of Health and Family Welfare, \\ Government of West Bengal, West Bengal, India
}

\begin{abstract}
On 10 March 2010, an outbreak of diarrhoeal disease was reported among workers of a jute mill in Kolkata, West Bengal, India. The cluster was investigated to identify the agent(s) and the source of infection and make recommendations. A suspected case of cholera was defined as having $\geq 3$ loose watery stools in a 24-hour period and searched for case-patients in the workers' colony. The outbreak was described by time, place, and person, and a case-control study was conducted to identify the source of infection. Rectal swabs were collected from the hospitalized case-patients, and the local water-supply system was assessed. In total, 197 case-patients were identified among 5,910 residents of the workers' colony (attack rate 3.33\%). Fifteen of 24 stool samples were positive for Vibrio cholerae O1. The outbreak started on $7 \mathrm{March}$, peaked on 11 March, and ended on 16 March 2010. Compared to 120 controls, 60 cases did not differ in terms of age and socioeconomic status. Drinking-water from the reservoir within the mill premises was associated with an increased risk of illness [odds ratio: 26.7, 95\% confidence interval (CI) 11.4-62.6) and accounted for most cases (population attributable risk percentage $=82 \%, 95 \%$ CI 70.8-92.9). An outbreak of cholera occurred among workers of the jute mill due to contamination of the drinking-water reservoir. It occurred within a few days of re-opening of the mill after the workers' strike. Health authorities need to enforce disinfection of drinking-water and regularly test its bacteriological quality, particularly before re-opening of the mill after the strike.
\end{abstract}

Key words: Case-control studies; Disease outbreaks; Cholera; Vibrio cholerae; Water pollution; Water supply; India

\section{INTRODUCTION}

Cholera, an acute infectious disease caused by toxigenic strains of Vibrio cholerae serogroup $\mathrm{O} 1$ and O139, is transmitted through contaminated water and food $(1,2)$. The enterotoxin produced by $V$. cholerae stimulates the secretion of water and electrolytes in the intestinal lumen. Patients with cholera may suffer from acute watery diarrhoea, vomiting, and dehydration but rarely present with fever $(1,2)$. Cholera continues to be an important health

Correspondence and reprint requests should be addressed to:

Dr. M.V. Murhekar

National Institute of Epidemiology

(Indian Council of Medical Research)

R-127, Tamil Nadu Housing Board

Ayapakkam, Ambattur

Chennai 600070

India

Email: mmurhekar@gmail.com

Fax: 91-44-26136426 problem in India. Sixty-eight outbreaks of cholera were reported from the country during 1997-2006, affecting more than 200,000 cases with 823 deaths. Nearly one-fourth of the outbreaks and $42 \%$ of deaths were from the Indian state of West Bengal. $V$. cholerae $\mathrm{O} 1$ belonging to the $\mathrm{El}$ Tor biotype is the most common serogroup in the country while the frequency of serogroup O139 has declined considerably over the past few years (3).

On 10 March 2010, the local Councilor of Ward no. 80 of the Kolkata Municipal Corporation (KMC), West Bengal, India, informed the corporation health authorities about a cluster of diarrhoeal diseases among the workers of a jute mill. Several of these case-patients were admitted to the Infectious Disease Hospital, Kolkata. We investigated this outbreak with the objectives of (a) estimating the magnitude, (b) identifying the aetiological agent and the source of infection, and (c) guiding the prevention and control measures. 


\section{MATERIALS AND METHODS}

\section{Descriptive epidemiology}

We reviewed the diarrhoeal disease surveillance data from the office of KMC for the previous five years to confirm the existence of the outbreak. We defined a suspected case of cholera as occurrence of three or more loose stools in a 24-hour period among the residents of a jute mill colony since 5 March 2010. A suspected case with isolation of $V$. cholerae was considered a confirmed case. This case definition was consistent with the case definition of the Integrated Disease Surveillance Project (IDSP) in India (4). We searched for case-patients by door-to-door visits in the workers' colony and collected information about the sociodemographic details of all the residents and clinical details, date of onset of illness, and place of residence from the case-patients.

We calculated the incidence by age and sex using population denominators collected during the house-to-house search. An epidemic curve was constructed to describe the distribution of case-patients over time. The cases were plotted on a spot-map to understand their geographical distribution. To formulate the hypothesis, we interviewed some case-patients to collect information about possible exposures, including drinking-water, drainage system, hygiene practices, and whether there was any common festival or mass gathering within a week of onset of the outbreak.

\section{Environmental investigations}

We visited the jute mill and the mill colony to inspect and review the water supply and sanitation system. Drinking-water samples were collected from all the water sources within the mill and also from the corporation tap-water sources in the workers' colony. Their bacteriological quality was tested.

\section{Laboratory investigations}

Rectal swabs were collected from a sample of casepatients admitted to the Infectious Disease Hospital during the course of the outbreak. Rectal swabs were sent to the National Institute of Cholera and Enteric Diseases (NICED), Kolkata, for microbiological investigations. Water samples taken from inside the mill and workers' colony were tested for coliforms by membrane-filtration technique at the water analysis department of the KMC.

Analytical epidemiology

We conducted an unmatched case-control study to test the hypothesis that the outbreak was associated with drinking-water from the reservoir in the mill premises. Assuming the confidence level of 95\%, power of $90 \%$, case:control ratio of $1: 2$, and $40 \%$ of the controls drinking water from this source, we calculated the sample-size of 60 cases and 120 controls to detect a minimum odds ratio of 3 . We included all the case-patients admitted to the hospital as cases and randomly selected two healthy persons from the employee register and staying in the workers' colony as controls. Using a pre-tested, close-ended structured questionnaire, we collected information regarding general characteristics, clinical features, and potential risk factors.

Univariate and multivariate analyses were conducted using the Epi Info software (version 3.3.2, 2005) of the Centers for Disease Control and Prevention (CDC), Atlanta, GA, USA. We calculated odds ratios (ORs) and their 95\% confidence intervals (CIs) for different exposures and estimated the attributable fraction and population attributable fractions using the OpenEpi software (version 2.2, 2007).

\section{RESULTS}

\section{Descriptive epidemiology}

Of the 5,910 residents in the workers' colony, 3,057 (52\%) were male. We identified 197 case-patients with an overall attack rate of $3.3 \%$, with no death. All the 197 case-patients were male (attack rate 6.4\%) and were working in the mill while none of the family members of the workers developed the illness. The attack rate was the highest (6\%) in the age-group of 45-54 years (Table 1). Of the 197 case-patients, 92\% had dehydration, $89 \%$ had vomiting, and $51 \%$ were hospitalized. Cases started occurring from 7 March, peaked on 11 March, and the outbreak subsided on 16 March 2010 (Fig.).

\begin{tabular}{|lccc|}
\hline Table 1. & \multicolumn{3}{c|}{$\begin{array}{l}\text { Distribution of suspected cholera cases by } \\
\text { age in the jute mill workers' colony, Kol- } \\
\text { kata, West Bengal, India, March 2010 }\end{array}$} \\
\hline $\begin{array}{l}\text { Age-group } \\
\text { (years) }\end{array}$ & Population & Cases & $\begin{array}{c}\text { Attack rate } \\
\text { (\%) }\end{array}$ \\
\hline $0-14$ & 1,271 & 0 & 0.0 \\
$15-24$ & 589 & 17 & 2.9 \\
$25-34$ & 959 & 32 & 3.3 \\
$35-44$ & 1,167 & 57 & 4.9 \\
$45-54$ & 1,113 & 66 & 5.9 \\
$55-64$ & 591 & 25 & 4.2 \\
$\geq 65$ & 220 & 0 & 0.0 \\
Total & 5,910 & 197 & 3.3 \\
\hline
\end{tabular}




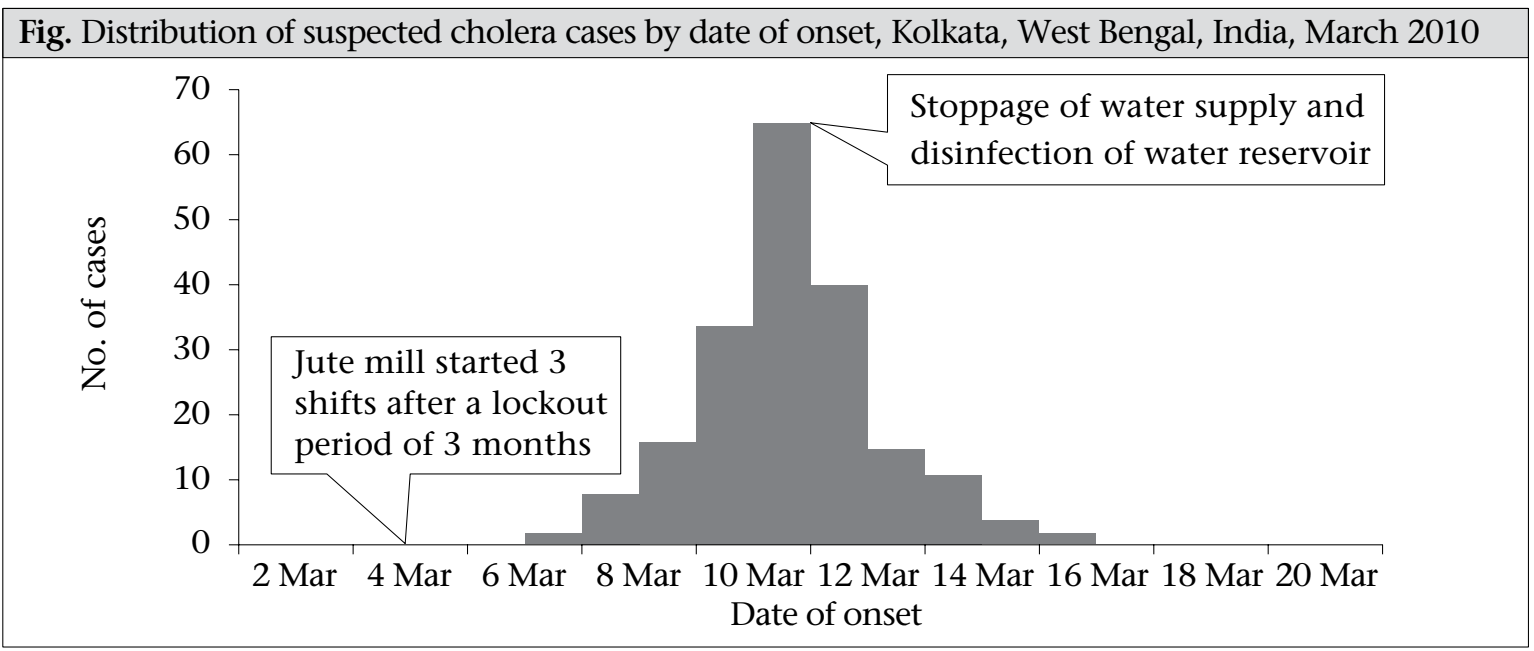

The spot-map of the residential area did not show any clustering (data not shown).

\section{Laboratory investigations}

V. cholerae $\mathrm{O} 1 \mathrm{El}$ Tor Ogawa was isolated from 15 of the 24 rectal swabs. All the five water samples from the water sources inside the factory (one from the overhead tank, one from the drinking-water reservoir, and three from water-taps, coming from the overhead tank) showed coliforms, indicating faecal contamination. On the other hand, all the four water samples from the KMC water-taps in the workers' colony had no coliforms.

\section{Environmental investigations}

The jute mill, situated by the side of the Hooghly river, existed for more than 100 years. The mill received water from two sources: (a) the underground water, which was stored in an overhead tank, was primarily used for industrial purposes and for domestic use, e.g. washing, bathing and (b) water supplied through the KMC was used for drinking purposes. This water was stored in the reservoir in the mill premises and distributed to the workers through three taps. Water from the KMC was supplied daily in adequate quantity. This reservoir also received water from the overhead tank that contained the underground water. The workers' colony received water from the $\mathrm{KMC}$.

The jute mill was closed during 14 December 200912 February 2010 due to the workers' strike. It was re-opened on 13 February 2010 and became operational on 5 March 2010, when more than 1,500 workers joined the work. Three weeks before the start of its operations, the mill management undertook the maintenance of mechanical equipment with a few workers (working for short duration).
The drinking-water reservoir, however, was not cleaned or disinfected.

\section{Analytical epidemiology}

The cases and controls did not differ by age (mean age of cases and controls: 41.7 and 41.8 years respectively, $\mathrm{p}=0.99$ ), education level (proportion of cases and controls educated up to primary level: $64 \%$ and $67 \%$ respectively, $\mathrm{p}=0.53$ ), and income (median monthly income of cases and controls: Rs 5,500, $\mathrm{p}=0.67)$. Compared to the controls, more case-patients drank water from the drinking-water reservoir within the compound of the mill during the duty hours (OR=26.7, 95\% CI 11.4-62.6). This exposure accounted for the majority of cases (attributable risk among exposed=96.3\%, 95\% CI 91.2-98.4 and population attributable risk=82\%, 95\% CI 70.8-92.9). Certain practices, such as washing hands before taking food and after defaecation, were associated with a lower risk of developing the illness (Table 2). On multiple logistic regression, the adjusted OR associated with drinking-water from the reservoir within the mill premises was 12.1 (95\% CI 4.3-34).

\section{Control measures}

After the onset of the outbreak, the factory authorities stopped the use of drinking-water from the reservoir within the mill premises. The reservoir and the overhead tank were disinfected on 11 March 2010, and the disinfection process was continued for three consecutive days.

\section{DISCUSSION}

An outbreak of cholera occurred in the jute mill in Kolkata within days after the factory was re-opened after the workers' strike. Our investigations pointed 


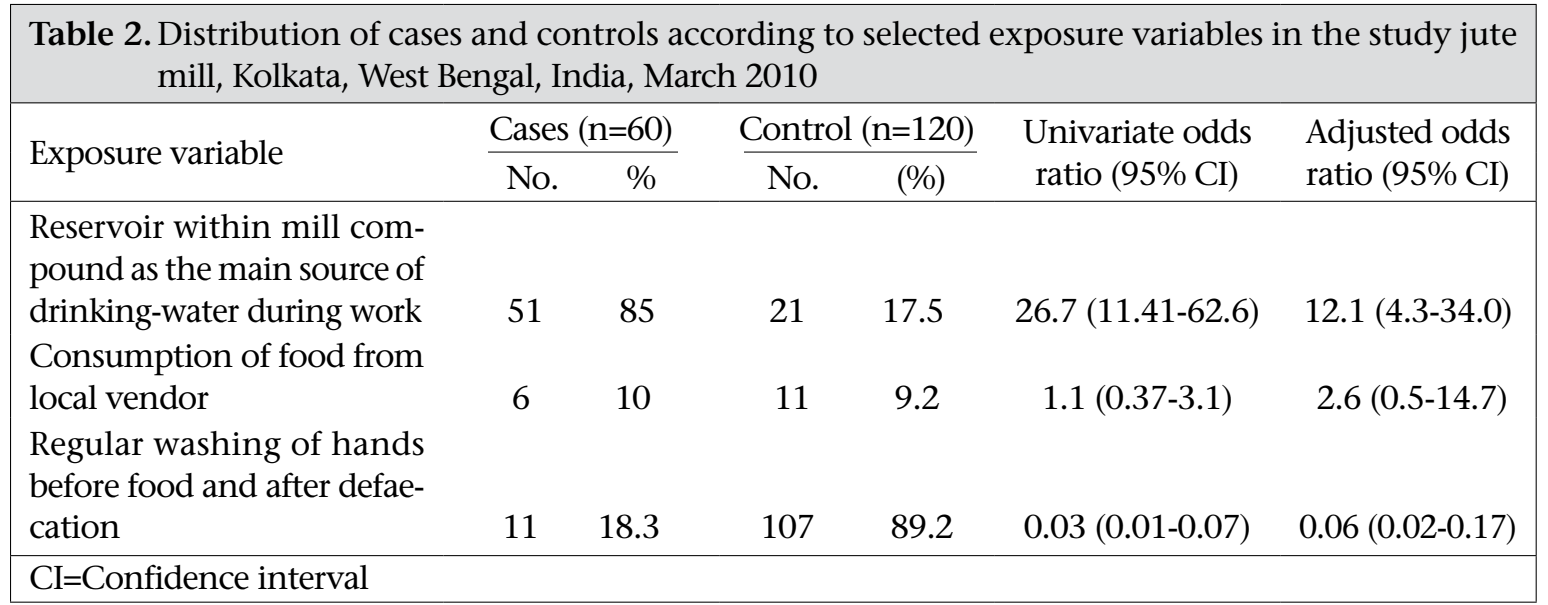

to the contamination of the drinking-water reservoir within the factory premises as the source of the outbreak, with more than $95 \%$ of the cases being attributed to this exposure. Prompt hospitalization of the cases, immediate discontinuation of the use of the drinking-water reservoir within the mill premises and its disinfection stopped the outbreak and prevented secondary cases in the workers' colony.

Several factors supported our finding that the outbreak was due to contamination of the drinkingwater reservoir within the mill premises. First, all the cases were identified among the factory workers, with no secondary cases among the residents of the workers' colony. Second, the shape of the epidemic curve supported exposure to a common source. Third, the consumption of drinking-water from this source was associated with an increased risk of illness, with more than $95 \%$ of the cases being attributed to this exposure. Fourth, the water samples from the drinking-water reservoir and overhead tank containing underground water were found to be faecally contaminated. Although we did not attempt to isolate $V$. cholerae from water, the findings of our investigation support our hypothesis that reservoir water was contaminated with $V$. cholerae. It appeared most likely that the drinkingwater reservoir was contaminated by underground water supplied through the overhead tank.

Outbreaks of cholera are common in West Bengal. For example, 16 outbreaks of cholera were reported during 1996-2007 from this state (3). These outbreaks were reported both from urban and rural areas and were due to contamination of drinkingwater sources, including wells [Das PK, Biswas A, Ramakrishnan R, Hutin Y, Gupte M. Unprotected wells continue to cause cholera outbreaks in West Bengal, India, 2006. Presented at: the Fourth SouthEast Asia and Western Pacific Bi-regional TEPHI-
NET Scientific Conference, 26-30 November 2007, Taipei, Taiwan, China], ponds [Rudra S, Ramakrishnan R, Hutin Y, Gupte M. A cholera outbreak in a village of West Bengal, India, 2006: the danger of using ponds for soiled clothes disposal. Presented at: the Fourth South-East Asia and Western Pacific Bi-regional TEPHINET Scientific Conference, 26-30 November 2007, Taipei, Taiwan, China], and piped water $(3,5,6)$. The present outbreak is the first one reported in a mill setting in West Bengal. Outbreaks of cholera due to contamination of drinking-water sources have been reported in other occupational settings, such as gold mines and oil rigs $(7,8)$.

According to the Factories Act of India, it is mandatory that every factory has effective arrangements for provision and maintenance of suitable drinking-water points, with all such points legibly marked as 'drinking-water' in a language understood by the majority of workers employed in the factory (9). The arrangements for drinking-water were adequate in the jute mill, although there was no signage for 'drinking-water'. Before making the factory operational after the workers' strike, the mill management undertook maintenance of mechanical equipment. This maintenance work was done by a small number of management staff and workers, and none of them developed illness as they did not consume water from the reservoir. The factory management, however, paid no attention to cleaning or disinfecting the water reservoir in the mill, thereby leading to an outbreak.

\section{Limitations}

Our investigation had certain limitations. First, we identified contamination of the drinking-water reservoir in the mill premises as the source of outbreak. This contamination might have occurred due to the mixing of underground water. We, however, were not able to explain how the underground reservoir 
was contaminated. Second, we only included admitted case-patients in the study. These case-patients are likely to recall more about water-consumption history compared to the healthy controls. However, such bias would be very small as the study subjects and the trained investigators were unaware of the hypothesis under investigation.

\section{Conclusions}

A large outbreak of cholera occurred among workers of a jute mill in Kolkata due to contamination of the water reservoir. This contamination probably occurred through the underground water supplied from the overhead tank. We made a number of recommendations and engaged several interventions. First, we educated the mill workers not to drink the reservoir water till the outbreak was over. Second, we disinfected the reservoir and recommended its periodic chlorination. Third, the connection between the reservoir and the overhead tank was closed and recommended to supply water for drinking from the city corporation only. The findings of our investigations would also be useful in preventing similar outbreaks in the state where jute textile manufacturing is the most prominent industry. The health authorities from the KMC and the Department of Health need to ensure that factory management disinfects the drinking-water reservoirs and tests these for their bacteriological quality before re-opening factories after workers' strike.

\section{ACKNOWLEDGEMENTS}

The authors thank the Joint Director (PH and CD), Department of Health, Director, NICED, Kolkata, Chief Health Officer, KMC, Chief Medical Officer of Health, South-24 Parganas, Executive Health Officer, Borough-IX KMC, Surveillance Medical Officer, IDSP, KMC, and the Water Analysist, KMC, for their support in this investigation. The authors acknowledge the help provided by Mr. Sailesh Singh in data collection.

\section{REFERENCES}

1. Kaper JB, Morris G, Jr., Levine MM. Cholera. Clin Microbiol Rev 1995;8:48-86.

2. Greenough WB, III. Vibrio cholerae. In: Mandell GL, Douglas GR, Benett JE, editors. Principles and practice of infectious diseases. 3rd ed. New York, NY: Churchill Livingstone, 1990:1636-45.

3. Kanungo S, Sah BK, Lopez AL, Sung JS, Paisley AM, Sur D et al. Cholera in India: an analysis of reports, 1997-2006. Bull World Health Organ 2010;88:185-91.

4. India. Directorate General of Health Services. Integrated Disease Surveillance Project: operational manual for District Surveillance Unit. New Delhi: Ministry of Health and Family Welfare, Government of India, 2005:17.

5. Sengupta PG, Mondal SK, Sur D, Dutta P, Gupta DN, Ghosh S et al. An explosive outbreak of Eltor cholera among migrant labourers of a brick field area near Calcutta. Indian J Community Med 2001;26:137-40.

6. Bhunia R, Ramakrishnan R, Hutin Y, Gupte MD. Cholera outbreak secondary to contaminated pipe water in an urban area, West Bengal, India, 2006. Indian J Gastroenterol 2009;28:62-4.

7. Isaäcson M, Clarke KR, Ellacombe GH, Smit WA, Smit $\mathrm{P}$, Koornhof $\mathrm{HJ}$ et al. The recent cholera outbreak in the South African gold mining industry. A preliminary report. S Afr Med J 1974;48:2557-60.

8. Johnston JM, Martin DL, Perdue J, McFarland LM, Caraway CT, Lippy EC et al. Cholera on a Gulf Coast oil rig. N Engl J Med 1983;309:523-6.

9. Factories Act 1948. Act no. 63. 1948. 71 p. (http:// pblabour.gov.in/pdf/acts_rules/factories_act_1948. pdf, accessed on 25 May 2010). 